\title{
Hydromorphone Measurement
}

National Cancer Institute

\section{Source}

National Cancer Institute. Hydromorphone Measurement. NCI Thesaurus. Code C74880.

The determination of the amount of hydromorphone present in a sample. 